\title{
Patients' Preference to Bedside Teaching Encounters in Four Major Wards in a Tertiary Care Centre
}

\author{
Calvin Ghimire, ${ }^{1}$ Sajan Acharya, ${ }^{1}$ Abhiskar Thapa, ${ }^{1}$ Asha Shrestha, ${ }^{1}$ Deep Basnet, ${ }^{1}$ Kripa Rajak \\ 'Patan Academy of Health Sciences, Lagankhel, Lalitpur, Nepal.
}

\section{ABSTRACT}

Introduction: Patient interaction is a vital aspect of medical education. Bedside teaching encounters involve clinicians, medical students, and patients, and comprise a formative and focused activity. Patients' willingness to cooperate and contribute to the education and training of medical students provide better teaching opportunities. The study aims to find the patients' preference to bedside teaching encounters in four major wards in a tertiary care center in Nepal.

Methods: This descriptive cross-sectional study was performed in four major wards in a tertary care centre from June 3, 2015 to July 3, 2015 after receiving ethical approval. Convenient sampling was done. Data was collected in Microsoft Excel and analyzed in Statistical Package for Social Sciences 13.0. Point estimate at $95 \%$ Confidence Interval was calculated along with frequency and proportion for binary data. Subgroup analysis was done on the basis of demographic variables.

Results:Seventy-eight (77.2\%) patients preferred bedside teaching encounters among 101 participants (77.12-77.28\%) at 95\% Confidence Interval. Among which, females, age ranging from 16 to 32 years, education below secondary school and with hospital stay<4 days were most common.

Conclusions: The results showed that most of the patients preferred bedside teaching encounters which was congruent with the other national and international studies.

Keywords: acceptability; communication; medical students.

\section{INTRODUCTION}

Interactions with patients are central to medical student education. Bedside teaching encounters (BTE) involve clinicians, medical students, and patients, and comprise a formative and focused activity through which students learn both the "what's" and "how's" of physicians." It can promote contextual and clinical learning, improve communication and professional skills and initiate the development of future doctor-patient relationships. ${ }^{2,3}$

Studies have shown that the likelihood of patients agreeing to be involved in medical education depends on the patient, the student and the procedure being undertaken. Patients' willingness to cooperate and contribute to the education and training of medical students provide better teaching opportunities..$^{2,3}$
The study aims to find the patients' preference to bedside teaching encounters in four major wards in a tertiary care center in Nepal.

\section{METHODS}

A descriptive cross-sectional study was conducted among 101 patients in Patan Hospital, Lalitpur, Nepal after obtaining ethical clearance. The study was conducted from $3^{\text {rd }}$ June to $3^{\text {rd }}$ July 2015. Patients with age $>16$ years from four major wards; surgery, medicine, orthopedics and gynecology/maternity were

Correspondence: Dr. Sajan Acharya, Patan Academy of Health Sciences, Lagankhel, Lalitpur, Nepal. Email: sajanacharya@gmail.com, Phone: +977-9849511470. 
included in the study. Patients who were below 16 years of age, who did not give consent, and who were mentally challenged, under psychiatric consultation and antipsychotic medications were excluded.

Sample size was calculated using the following formula,

$$
\begin{aligned}
\mathrm{n} & =\mathrm{Z}^{2} \times(\mathrm{p} \times \mathrm{q}) / \mathrm{e}^{2} \\
& =(1.96)^{2} \times(0.5 \times 0.5) /(0.1)^{2} \\
& =(3.84) \times(0.25) /(0.01) \\
& =96.04 \\
\text { Where } & \\
\mathrm{n} & =\text { sample size } \\
\mathrm{p} & =\text { prevalence, } 50 \% \\
\mathrm{q} & =1-\mathrm{p} \\
\mathrm{e} & =\text { margin of error, } 10 \% \\
\mathrm{Z} & =1.96 \text { at } 95 \% \mathrm{Cl}
\end{aligned}
$$

Sample size calculated was 97. Taking non-response rate of $4 \%$, the final sample size was 101 . Convenient sampling was done.

A pre-validated questionnaire was adopted from a study organized in teaching hospitals of the Faculty of Medicine of Kuwait University. ${ }^{4}$

Data was collected and entered in Microsoft Excel and analyzed in Statistical Package for Social Sciences version 13.0. Point estimate at 95\% Confidence Interval was calculated and frequency and proportion for binary data. Subgroup analysis was done on the basis of age, gender, days of hospital admission.

\section{RESULTS}

Seventy-eight (77.2\%) patients preferred BTE among 101 participants $(77.12-77.28 \%$ at $95 \%$ Cl). Similarly, $23(22.7 \%)$ patients did not prefer BTE. Fifty-five (80\%) females preferred BTE than males among those who preferred BTE. Similarly, those with age group 1632 years, education of below secondary and stayed in hospital for $<4$ days preferred BTE (Table 1).

\begin{tabular}{|lll|}
\hline \multicolumn{2}{|l|}{$\begin{array}{l}\text { Table 1. Demographic characteristics of participants } \\
\text { who preferred BTE. }\end{array}$} \\
\hline $\begin{array}{l}\text { Demographic } \\
\text { variables }\end{array}$ & Division \\
Gender & Male & $23(20)$ \\
Age & Female & $55(80)$ \\
& $16-32$ years & $45(57.6)$ \\
& $32-84$ years & $33(42.3)$
\end{tabular}

\begin{tabular}{|lll|} 
& Illiterate & $14(17.9)$ \\
& Below Secondary & $30(38.46)$ \\
& $\begin{array}{l}\text { Below Higher } \\
\text { Secondary }\end{array}$ & $15(19.23)$ \\
& Below Bachelors & $15(19.23)$ \\
& $\begin{array}{l}\text { Masters and } \\
\text { above }\end{array}$ & $4(5.12)$ \\
Hospital Stay & $>4$ days & $28(35.89)$ \\
& $<4$ days & $50(64.1)$ \\
\hline
\end{tabular}

Fifty-six (55.4\%) patients mentioned that it would improve the quality of healthcare, 35 (33.7\%) mentioned it would have no effect on the quality of healthcare provided and 10 (9.9\%) mentioned it would worsen the quality of health care (Figure 1).

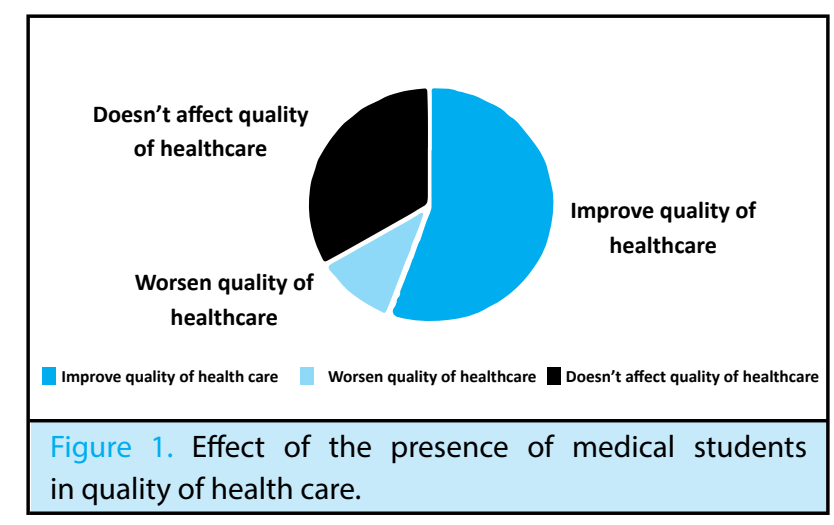

\section{DISCUSSION}

Seventy-eight (77.2\%) patients preferred BTE among 101 participants. The results in our study were congruent with other national and international studies. $^{5-7}$ Many larger studies do not suggest that a healthcare facility's teaching status on its own markedly improves or worsens patient outcomes. ${ }^{8,9}$ In a similar study organized in teaching hospitals of the faculty of medicine of Kuwait university conducted in 995 patients in 14 teaching hospitals higher acceptance of students by patients was found. Echoing our study majority of the patients in their study, 436 (46.8\%) patients believed that the presence of medical students in hospitals improves the quality of health care. ${ }^{1}$ Studies from different parts of the world imply positive connotations to the presence of medical students in the ward.9-12 Frequent and larger studies in this domain can assist medical schools in designing their curriculum and help patients understand the importance of training medical students. It also helps develop an institutional culture of gratitude towards patients who really are 
the most important part of medical education. ${ }^{13,14}$ Many studies conclude that even unprepared patients see themselves as contributors to teaching, and their capacity in this respect is probably under-utilized. ${ }^{12}$

The limitation of our study is as this study was conducted in smaller settings so the results cannot be generalized. It is highly recommended for the study to be done in larger settings.

\section{CONCLUSIONS}

The result showed that most of the patients preferred bedside teaching encounters which was congruent with the other national and international studies.

\section{ACKNOWLEDGEMENTS}

It's our pleasure to thank all the doctors, nurses and staff of medicine ward, gynecology ward, orthopedics ward and surgical ward for their cooperation and support. We are in debt to all the patients for their invaluable support, co-operation and time in making this research a success.

Conflict of Interest: None.

\section{REFERENCES}

1. Monrouxe LV, Rees CE, Bradley P. The construction of patients' involvement in hospital bedside teaching encounters. Qual Health Res. 2009 Jul;19(7):918-30. [PubMed | Full Text | DOI]

2. Chipp E, Stoneley S, Cooper K. Clinical placements for medical students: factors affecting patients' involvement in medical education. Med Teach. 2004 Mar;26(2):114-9. [PubMed | Full Text $\mid \underline{\text { DOI] }}$

3. Passaperuma K, Higgins J, Power S, Taylor T. Do patients' comfort levels and attitudes regarding medical student involvement vary across specialties? Med Teach. 2008;30(1):48-54. [PubMed | Full Text | DOI]

4. Marwan Y, Al-Saddique M, Hassan A, Karim J, Al-Saleh M. Are medical students accepted by patients in teaching hospitals? Med Educ Online. 2012;17:10. Epub 2012 Apr 11. [PubMed | Full Text | DOI]

5. Sayed-Hassan RM, Bashour HN, Koudsi AY. Patient attitudes towards medical students at Damascus University teaching hospitals. BMC Med Educ. 2012 Mar 22;12:13. [PubMed | Full Text | DOI]

6. Kianmehr N, Mofidi M, Yazdanpanah R, Ahmadi MA. Medical student and patient perspectives on bedside teaching. Saudi Med J. 2010 May;31(5):565-8. [PubMed | Full Text]

7. Cooke F, Galasko G, Ramrakha V, Richards D, Rose A, Watkins J. Medical students in general practice: how do patients feel? Br J Gen Pract.1996 Jun;46(407):361-2. [PubMed | Full Text]
8. Salisbury K, Farmer EA, Vnuk A. Patients' views on the training of medical students in Australian general practice settings. Aust Fam Physician. 2004 Apr;33(4):281-3. [PubMed | Full Text]

9. Manninen K, Henriksson EW, Scheja M, Silen C. Patients' approaches to students' learning at a clinical education ward-an ethnographic study. BMC Med Educ. $2014 \mathrm{Jul}$ 2;14:131. [PubMed | Full Text | DOI]

10. McLachlanE, King N, WengerE, Dornan T.Phenomenological analysis of patient experiences of medical student teaching encounters. Med Educ. 2012 Oct;46(10):963-73. [PubMed |

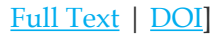

11. Morgan A, Jones D. Perceptions of service user and career involvement in healthcare education and impact on students' knowledge and practice: a literature review. Med Teach. 2009 Feb;31(2):82-95. [PubMed | Full Text | DOI]

12. Haffling AC, Håkansson A. Patients consulting with students in general practice: Survey of patients' satisfaction and their role in teaching. Med Teach. 2008;30(6):622-9. [PubMed |

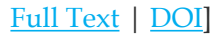

13. Papanikolaou PN, Christidi GD, Ioannidis JP. Patient outcomes with teaching versus nonteaching healthcare: a systematic review. PLoS Med. 2006 Sep;3(9):e341. [PubMed | Full Text | DOI]

14. Sheldon TA. The volume-quality relationship: Insufficient evidence for use as a quality indicator. Qual Saf Health Care. 2004 Oct;13(5):325-6. [릴ed | Full Text | DOI] 